\title{
EVALUATION OF TOILET HABITS AND SELF-AWARENESS OF CONSTIPATION STATUSES AMONG YOUNG ADULTS FROM DIFFERENT FACULTIES AT ACIBADEM UNIVERSITY
}

\author{
Nisanur Kaygısız ${ }^{1}$ (D) Atahan Durbaş $^{1}$ (D), Hüseyin $\operatorname{Karaman}^{1}$ (D), \\ Çağla Hamide Solman ${ }^{1}$ (D), Özdal Ersoy ${ }^{2}$ (i)
}

${ }^{1}$ Acıbadem Mehmet Ali Aydınlar University School of Medicine, Istanbul, TURKEY

${ }^{2}$ Department of Gastroenterology, Acıbadem International Hospital, Istanbul, TURKEY

\begin{abstract}
Aims: To evaluate Acibadem University students' self-awareness of their constipation statuses and investigate whether there is an association between constipation and prolonged sitting time in the toilet affected by toilet habits. Methods: This cross-sectional study was conducted from March 7 to April 3, 2019, at Acibadem Mehmet Ali Aydınlar University. The questionnaire consists of 3 parts and a total of 16 questions. The first part asked about the participants' gender, age, faculty, and school year to collect their demographic information. The second part investigated participants' awareness of constipation and factors affecting constipation. The last part included questions about toilet habits and their sitting time in the toilet. The constipation status of participants was evaluated using the Rome IV Diagnostic Criteria and the self-awareness of participants about their constipation statuses was assessed. Results: 293 students from 5 different faculties (Medicine, Pharmacy, Medical Engineering, Nutrition and Dietetics, and Psychology) of Acıbadem University participated in our study. Our results showed that $22.54 \%$ of students were appeared to be constipated. Out of all the students, $24.45 \%$ of them were unaware that they were constipated. The use of smartphones was the most common toilet habit, and it increased the time spent sitting on the toilet. Constipation was seen at higher rates among students who spent a longer time on the toilet. Conclusion: Our study demonstrated that having toilet habits increased the time spent sitting on the toilet. Our study also found that as the time spent on the toilet increased, the prevalence of constipation among participants increased accordingly. Poor eating habits and sedentary lifestyles of young adults may have a cumulative effect on constipation. Raising public awareness regarding proper defecation routines and limiting toilet habits and sitting time on the toilet seems essential to prevent constipation. Keywords: Constipation, toilets habits, lifestyle, smartphone, young adult
\end{abstract}

\section{INTRODUCTION}

Constipation can be defined as infrequent defecation or hard passage of stools (1). The prevalence of constipation is $8.3 \%$ in Turkey (2) and approximately $20 \%$ around the world (3-5), being one of the most common gastrointestinal complaints. However, it is still difficult to determine the exact prevalence of constipation since self-reported constipation is a subjective complaint dependent on the self-awareness and the definition used to identify "constipation". It has also been shown that self-reported constipation findings are neither sensitive nor specific compared to constipation diagnosis made with symptom-based criteria (5-7). The Rome IV Diagnostic Criteria are expert consensus criteria that have long been used by gastroenterologists for the diagnosis and classification of functional gastrointestinal disorders $(8,9)$. One of the criteria for the diagnosis of functional constipation is lumpy or hard stool defecation which is classified as Type 1 and Type 2 according to the Bristol Stool Form Scale is widely used in clinical practice for stool form measurement $(10,11)$. Additionally, many factors alter the prevalence of constipation such as age, gender, eating habits, water consumption, and physical activity (12-14). The prevalence of constipation increases in the elderly since the colonic transit time slows down with age.
Moreover, women are 1.5 times more likely to be constipated than men (3). Insufficient fluid intake can also be one of the causative factors for constipation by forming a hard stool (15).

The study conducted by Dehn et al. (16) demonstrated the relationship between toilet habits and the risk of hemorrhoids. Goldstein et al. (17) attempted to examine the relationship between constipation and reading habits during defecation. However, this study included many bowel diseases besides constipation, and only toilet reading was questioned. In a recently published paper, Berney (18) stated that over the last few years they have been getting a lot of complaints from young adults with no significant risk factors referred to them with symptomatic hemorrhoidal disease. He found that the patients mostly reported prolonged sitting time on the toilet due to frequent smartphone usage therefore decided to ask patients presenting with gastrointestinal symptoms about their smartphone usage during their time on the toilet (18). In his paper, he named this situation the "Smartphone Lavatory Syndrome" (18). The study by Çelik (19) attempted to investigate the relationship between hemorrhoid incidence and smartphone use in Turkey, however, the study is not yet completed.

This study aims to evaluate Acrbadem University students' self-awareness of their constipation statuses and investigate whether 
there is an association between constipation and prolonged sitting time on the toilet induced by toilet habits.

\section{MATERIAL AND METHODS}

\section{Research design}

Our study was approved by the Acibadem University Medical Research Ethics Committee (Protocol Code: ATADEK 2019-4/7). Informed consent was obtained from the students before they participated in the study. This study was conducted from March 7 to April 3, 2019, at Acıbadem Mehmet Ali Aydınlar University. The questionnaire in the Turkish language was carried out as handouts and distributed to participants via an interviewer. The questionnaire consists of 3 parts and a total of 16 questions (Table 1).
The first part asked about the participants' gender, age, faculty, and grade to collect their demographic information. The second part investigated participants' awareness of constipation and factors affecting constipation (accommodation, water and fiber consumption, physical activity). The last part included questions about toilet habits (what they do on the toilet during defecation) and their sitting time on the toilet. Participants had to complete at least half of the questionnaire to be included in the study. The participants who completed less than half of the questionnaire were excluded from the study. Moreover, participants who completed more than half of the questionnaire but did not answer particular questions were excluded for only the questions that they did not answer. Additionally, participants were able to choose more than one option for the last question which asked about their toilet habits.

Table 1: The questionnaire used in the study.

\begin{tabular}{l}
$\qquad$ Questions \\
\hline 1st Part: Demographics of Participants \\
\hline 1) Gender \\
2) Age \\
3) Which faculty are you enrolled in? \\
4) Which year are you enrolled in?
\end{tabular}

2nd Part: Awareness of Constipation and Factors Affecting Constipation

5) Which of the following do you think describes constipation?

6) Do you think you are constipated?

7) Please mark the criteria below that you have in at least 1 of every 4 stools ( $\geq 25 \%)$ :

\begin{abstract}
8) Choose the one that suits you from the following accommodation types:
9) Do you think you are eating a healthy and balanced diet?
\end{abstract}

10) How often do you consume fiber-rich foods such as fruits, vegetables, legumes, and cereals?

11) How much water do you drink in a day approximately? (1 glass of water is about $200 \mathrm{~mL}$ )

12) When you think about your normal day, how active do you think you are?

3rd Part: Toilet Habits and Sitting Time on the Toilet

13) How often do you defecate?

14) Do you have abdominal pain and/or abdominal bloating, discomfort that you feel relieved of when you go to the toilet?

15) Approximately how long do you stay on the toilet when you go to defecate? (in minutes)

16) Are you being busy with something else while defecating?

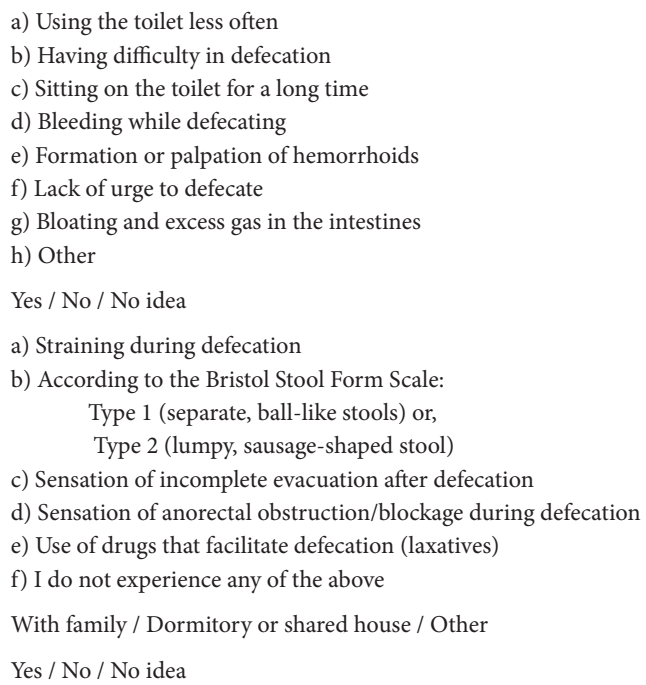

Every day / Few times a week / Once a week / Few times in a month / Once a month

$<1 \mathrm{~L} / 1-2 \mathrm{~L} / 2-3 \mathrm{~L} />3 \mathrm{~L}$

I go on a walk every day / I go on a walk every other day / I go on a walk at least 3 days a week / I go on a walk once a week / I do not go on a walk routinely / Other (you can write down other sports you practice)

More than once a day / Every day / More than 3 times a week / Less than 3 times a week Yes / No

$<5 / 5-10 / 10-15 / 15-20 />20$
a) Smoking
b) Reading newspaper/ magazine
c) Solving puzzle/sudoku
d) Using cellphone/tablet
e) Other
f) None

The participants were able to choose more than one option for the 5th, 7th and 16th questions. 
In the questionnaire, the Rome IV Diagnostic Criteria (Table 2) was used to diagnose whether participants are constipated or not (12). Furthermore, the Bristol Stool Form Scale (Figure 1) was added to the questionnaire to classify the participants' shape of stool (13). Besides, participants were asked to define constipation and indicate whether they think they are constipated or not to determine the participants' self-awareness of constipation. The 5th question aimed to determine the level of personal knowledge of constipation based on how well the participant knew the definition of constipation. If the participants who chose the correct definition of constipation here chose themselves as constipated in question 6 and were evaluated as constipated according to the Rome IV Diagnostic Criteria in question 7, this participant was considered to be "selfaware" of their constipation status, and the opposite situation was also valid. Therefore, the participant's self-awareness was a complex outcome that has emerged as a result of the analysis of the answers to more than one question. The participants' toilet habits were also investigated in the questionnaire. According to expert opinion, it is not recommended to sit on the toilet for more than 5 minutes. However, a span of 5 minutes may not be a very long time for the participants to notice that they have been sitting on the toilet for too long. Therefore, to ask if the participants had been sitting on the toilet for too long, the 10 minutes was deemed more appropriate to be included in the questionnaire.

Table 2: Rome IV Diagnostic Criteria for functional constipation.

\section{Must include two or more of the following:}

1. Lumpy or hard stools (Bristol Stool Form Scale 1-2) more than $1 / 4$ (25\%) of defecations

2. Sensation of incomplete evacuation more than $1 / 4(25 \%)$ of defecations

3. Sensation of anorectal obstruction/blockage more than $1 / 4$ (25\%) of defecations

4. Manual maneuvers to facilitate more than $1 / 4(25 \%)$ of defecations (e.g., digital evacuation, support of the pelvic floor)

5. Fewer than three spontaneous bowel movement per week

6. Loose stools are rarely present without the use of laxatives

7. Insufficient criteria for irritable bowel syndrome

Criteria fulfilled for the last 3 months with symptom onset at least 6 months prior to diagnosis.

\begin{tabular}{|ll|}
\hline Type 1 & Separate hard lumps, like nuts \\
\hline Type 2 & $\begin{array}{l}\text { Like a sausage but with } \\
\text { cracks on the surface }\end{array}$ \\
\hline Type 3 & $\begin{array}{l}\text { Like a sausage or snake, } \\
\text { smooth and soft }\end{array}$ \\
\hline Type 4 & $\begin{array}{l}\text { Soft blobs with clear-cut } \\
\text { edges }\end{array}$ \\
\hline Type 6 & $\begin{array}{l}\text { Fluffy pieces with ragged } \\
\text { edges, a mushy stool }\end{array}$ \\
\hline Type 7 & Watery, no solid pieces. \\
\hline
\end{tabular}

Figure 1: Bristol Stool Form Scale (11).

(C) 2016 Rome Foundation, Inc. All Rights Reserved. Reprinted with permission from the Rome Foundation; all rights reserved.)

\section{Data analysis}

The data were analyzed using Microsoft Excel (2016). The variables were tested for normal distribution by the Shapiro-Wilk Test. A p-value $<0.05$ was set for statistical significance. Numbers, percentages, mean, and standard deviation were used as the descriptive statistics for this study. Categorical variables were compared by using the Chi-squared test. The multivariate linear regression analysis was used to predict the value of constipation on the value of variables such as gender, age, accommodation, fiber consumption, water consumption, and physical activity.

\section{RESULTS}

This study was conducted on 293 students from the most populated 5 faculties of Acıbadem Mehmet Ali Aydınlar University. The results of this study were evaluated based on the answers of 291 students since 2 participants were excluded from the statistical analysis as they did not meet the inclusion criteria. A total of 80 medical students, 63 nutrition and dietetics students, 82 psychology students, 29 medical engineering students, and 39 pharmacy students were included in the study. The mean age of the students was $20.43 \pm 1.73$ years. Demographics of the participants are presented in Table 3.

Table 3: Demographics of participants.

\begin{tabular}{lc} 
& Number of Students [n (\%)] \\
\hline Gender & \\
Male & $67(23.0)$ \\
Female & $223(76.6)$ \\
Not specified & $1(0.3)$ \\
Age Group (years) & \\
$\mathbf{1 8 - 2 0}$ & $169(58.1)$ \\
$\mathbf{2 1 - 2 3}$ & $117(40.2)$ \\
$>\mathbf{2 3}$ & $5(1.7)$ \\
Grade & \\
$\mathbf{1}$ & \\
$\mathbf{2}$ & $87(29.8)$ \\
$\mathbf{3}$ & $120(41.2)$ \\
$\mathbf{4}$ & $63(21.6)$ \\
Faculty & $21(7.2)$ \\
Medicine & \\
Nutrition and Dietetics & \\
Pharmacy & $80(27.5)$ \\
Medical Engineering & $62(21.3)$ \\
Psychology & $38(13.1)$ \\
\hline
\end{tabular}

According to the Rome IV Diagnostic Criteria, 64 (22.54\%) participants were found constipated. Out of 291 participants, 45 (15.46\%) of them described themselves as constipated. Out of 45 participants who described themselves as constipated, 34 (75.56\%) of them were truly constipated according to the Rome IV Diagnostic Criteria. Moreover, 17 of 291 participants (5.84\%) did not have an idea about their constipation statuses. The self-awareness of students on their constipation statuses is presented in Figure 2 and Figure 3. Medical students had the highest rate of awareness with $94.26 \%$ whereas nutrition and dietetics students were found to have the lowest awareness with $69 \%$. Pharmacy, medical engineering, and psychology students' awareness rates were $85 \%, 82.96 \%$, and $80.14 \%$, respectively. 


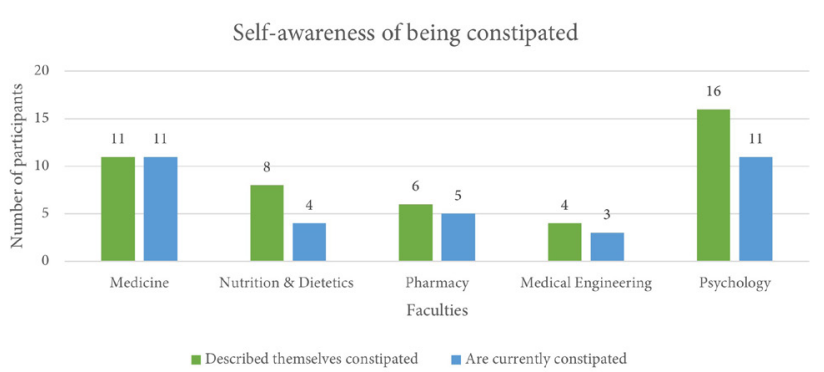

Figure 2: The comparison of students (Faculties of Medicine, Nutrition and Dietetics, Pharmacy, Medical Engineering, Psychology, respectively) according to their self-awareness on their constipation statuses (i.e. who was diagnosed as constipated and also defined themselves constipated as well).
Self-awareness of not being constipated

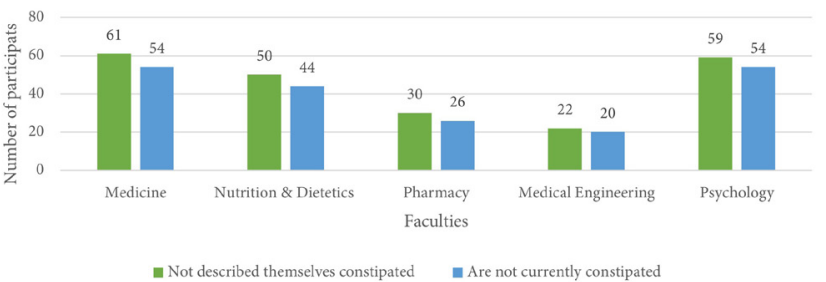

Figure 3: The comparison of students (Faculties of Medicine, Nutrition and Dietetics, Pharmacy, Medical Engineering, Psychology, respectively) according to their self-awareness on their constipation statuses (i.e. who was not diagnosed as constipated and also did not defined themselves constipated as well).

Table 4: Results of multivariate analysis with gender, age, accommodation type, fiber consumption, water consumption and physical activity as independent variables and constipation as the dependent variable.

\begin{tabular}{|c|c|c|c|c|c|}
\hline Independent variables & & $\begin{array}{c}\text { Beta } \\
\text { coefficients }\end{array}$ & $\begin{array}{c}\text { Standard } \\
\text { Error }\end{array}$ & t Stat & P-value \\
\hline Intercept & & -0.077 & 0.100 & -0.768 & 0.443 \\
\hline Gender & Female / Male & 0.159 & 0.062 & 2.547 & 0.011 \\
\hline Age & $>20 /=<20$ & -0.002 & 0.050 & -0.041 & 0.967 \\
\hline Accommodation type & Dormitory / House & 0.150 & 0.049 & 3.062 & 0.002 \\
\hline Fiber consumption & Everyday / Not everyday & 0.023 & 0.052 & 0.436 & 0.663 \\
\hline Water consumption & $=>2 L /$ Less than $2 L$ & -0.119 & 0.059 & -2.038 & 0.042 \\
\hline Physical activity & At least 3 times a week / Less 3 times a week & -0.003 & 0.053 & -0.051 & 0.960 \\
\hline
\end{tabular}

The multivariate linear regression analysis of different variables that could play a role in constipation is presented in Table 4. A significant regression equation was found $(\mathrm{F}(8.273)=4.066025$, $\mathrm{p}<0.001$ ) with an R2 of 0.11 . According to participants' characteristics and preferences; gender, water consumption, and types of accommodation were significant predictors of the constipation status of participants ( $\mathrm{p}=0.01, \mathrm{p}=0.04, \mathrm{p}=0.002$, respectively). $28.24 \%$ of participants who were staying in a dormitory or a shared house were found to be constipated, while only $14.51 \%$ of participants who lived with their families were found to be constipated. Fiber consumption and physical activity were not significant factors for determining constipation status ( $\mathrm{p}=0.66$ and $\mathrm{p}=0.95$, respectively). Smartphone/tablet use (69.76\%) was the most common toilet habit among participants, whereas the rates of smoking, reading newspaper/magazines, and solving puzzles/sudoku were $5.5 \%, 4.12 \%$, and $2.41 \%$, respectively. 79 participants $(27.15 \%)$ stated that they had no toilet habits. 81 of the participants who had at least one toilet habit, also had prolonged sitting time ( $>10$ minutes) on the toilet. Table 5 shows that having toilet habits and prolonged sitting time on the toilet were significantly associated, $(\chi 2(1, N=291)=12.569$, p-value $<0.001)$. Furthermore, 26 of the participants who were diagnosed as constipated according to Rome IV Diagnostic Criteria also had
Table 6: The relationship between time spent on the toilet and state of constipation presented as numbers of participants $(p$-value $=0.001)$.

\begin{tabular}{cccc} 
& $\begin{array}{c}\text { Diagnosed as } \\
\text { constipated } \\
(\boldsymbol{n})\end{array}$ & $\begin{array}{c}\text { Not diagnosed } \\
\text { as constipated } \\
(\boldsymbol{n})\end{array}$ & Total \\
\hline $\begin{array}{c}\text { Sits on the toilet more } \\
\text { than 10 minutes }\end{array}$ & 26 & 46 & 72 \\
$\begin{array}{c}\text { Sits on the toilet less } \\
\text { than 10 minutes }\end{array}$ & 38 & 174 & 212 \\
$\quad$ Total & 64 & 220 & $\mathbf{2 8 4}$ \\
\hline
\end{tabular}

(7 participants were excluded from the statistical analysis due to the incomplete filling of the questionnaire.)

prolonged sitting time on the toilet. As shown in Table 6, being constipated and having a prolonged sitting time on the toilet had a significant association $(\chi 2(1, \mathrm{~N}=284)=10.183$, $\mathrm{p}$-value $=0.001)$. 60 participants who were diagnosed as constipated also had toilet habits. However, as shown in Table 7 , there was no significant association between being constipated and having toilet habits $(\chi 2(1$, $\mathrm{N}=284)=3.293$, $\mathrm{p}$-value $=0.07$ ).

Table 5: The relationship between participants' toilet habits and their time spent on the toilet presented as numbers of participants (p-value $<0.001)$.

Toilet Habits

\begin{tabular}{|c|c|c|c|c|c|c|c|}
\hline Time spent on the toilet & Phone/tablet (n) & Newspaper/magazine $(n)$ & Puzzle (n) & Smoking (n) & Other $(n)$ & None $(n)$ & Total \\
\hline More than 10 minutes & 63 & 6 & 4 & 5 & 3 & 10 & 91 \\
\hline Less than 10 minutes & 141 & 6 & 3 & 11 & 2 & 69 & 232 \\
\hline Total & 204 & 12 & 7 & 16 & 5 & 79 & 323 \\
\hline
\end{tabular}

(Participants were allowed to choose more than one toilet habit.) 
Table 7: Relationship of toilet habits and state of constipation presented as numbers of participants. Participants could choose more than one answer about their toilet habits if they have ( $p$-value $=0.07)$.

Toilet Habits

\begin{tabular}{|c|c|c|c|c|c|c|c|}
\hline & Phone/Tablet (n) & Newspaper/Magazine (n) & Puzzle (n) & Smoking $(n)$ & Other (n) & None $(n)$ & Total \\
\hline $\begin{array}{l}\text { Diagnosed as } \\
\text { constipated }\end{array}$ & 50 & 2 & 3 & 5 & 0 & 12 & 72 \\
\hline $\begin{array}{c}\text { Not } \\
\text { diagnosed as } \\
\text { constipated }\end{array}$ & 149 & 9 & 3 & 10 & 3 & 65 & 239 \\
\hline Total & 199 & 11 & 6 & 15 & 3 & 77 & 311 \\
\hline
\end{tabular}

\section{DISCUSSION}

Although the use of smartphones and tablets on the toilet is very common, there are not many studies on the effects of using smartphones on the toilet on defecation disorders in the light of the literature. To our knowledge, this is the first study to present the frequency of toilet habits and the self-awareness of constipation statuses among young adults. Our study showed that having toilet habits was fairly common and was present in $72.85 \%$ of our participants. A study by Goldstein et al. (17) evaluated the prevalence of toilet reading habits in the Israeli adult population and found that toilet reading was prevalent in $52.7 \%$ of adults. In comparison, our study questioned several toilet habits such as the use of smartphones, solving puzzles, and smoking in addition to reading printed materials such as books, newspapers, and magazines. In contrast to the results of the aforementioned study, smartphone/tablet (69.76\%) was found to be the most prominent habit in our study.

According to the literature, people with relatively unhealthy lifestyles and bad eating habits are more likely to experience constipation (13). However, our study did not show any significant association between constipation and fiber consumption or physical activity. On the other hand, types of accommodation and water consumption were significantly associated with constipation. Participants who stated that they live with families were found to be less constipated. This may be attributed to having more organized lifestyles and finely regulated circadian rhythm which controls gut motility $(20,21)$. Since less fluid consumption can increase the likelihood of constipation, the recommendation to increase fluid intake for patients with constipation will be appropriate. Consequently, the type of accommodation and water consumption are significantly related to constipation. Therefore, to prevent and treat constipation in young adults, it is important for them to consume sufficient water and accommodate in a regular place that supports their circadian rhythms.

Another key finding in our study was that participants who had at least one toilet habit were found to be more constipated. $25.7 \%$ of participants who had toilet habits were constipated while only $15.5 \%$ of participants who did not have any toilet habits were constipated. However, our study did not find any significant association between toilet habits and constipation. It seems that extensive smartphone use during defecation $(69.76 \%)$ is not a distinctive factor in our study population due to its popularity among both constipated and non-constipated participants. Since young adults lead smartphone use in the general population, further studies may be conducted in a broader age group to provide more accurate results (22). Since the rate of smartphone use is lower in other age groups, this could act as a distinctive factor (22).
Our study showed that having toilet habits was significantly associated with prolonged sitting time ( $>10$ minutes) on the toilet. Having constipation and prolonged sitting time on the toilet was also found to be significantly associated. Such a result can be attributed to the expulsion of hard and lumpy stools, which requires more time since it takes more force and coercion to expel the hard stools. However, prolonged sitting on the toilet can lead to hemorrhoids and exacerbate constipation (16). Based on these findings, it seems necessary to raise public awareness by training on reducing the prevalence of anorectal disorders and limiting toilet habits and the time spent on the toilet. Medical students were the group with the highest awareness of constipation in our study, possibly more familiar with the symptoms that contribute to constipation, given their medical education. Similarly, if constipation becomes more recognized by the public, adjusting some routines on their own, such as increasing water intake, limiting toilet habits, and time spent on the toilet, will help alleviate patients' symptoms and complaints.

Our study provided an integrated approach to constipation that includes many independent variables. However, several potential limitations arose due to the demographics of our population. The fact that women were in the majority at the Acibadem University at the time of the survey may have created a gender imbalance. Further studies may involve a wider age group and a more balanced gender distribution.

In conclusion, having toilet habits is a common trait that may increase the time spent sitting on the toilet, which can lead to issues in the anorectal system. Moreover, young adults with toilet habits tend to be more constipated, although a significant association has yet to be shown. Constipation status and time spent on the toilet were found to be significantly associated. Water intake and type of accommodation were found to be significantly associated with constipation. Raising public awareness regarding proper defecation routines and limiting toilet habits and sitting time on the toilet seems essential to prevent constipation.

Ethics Committee Approval: This study was approved by the Acibadem University Medical Research Ethics Committee (Protocol Code: ATADEK 2019-4/7).

Informed Consent: Written informed consent was obtained from the participants of this study.

Conflict of Interests: The authors declared no conflict of interest.

Author contributions: Concept: NK, AD, HK, CHD. Design: NK, AD, HK, CHD. Supervision: OE. Resources: NK, AD, HK, CHD. Materials: NK, AD, HK, CHD. Data Collection and/or Processing: NK, AD, HK, CHD. Analysis and/or Interpretation: NK, AD, HK, CHD. Literature Search: NK, AD, HK, CHD. Writing Manuscript: NK, AD, HK, CHD. Critical Review: NK, AD, $\mathrm{HK}, \mathrm{CHD}, \mathrm{OE}$.

Financial disclosure: The authors declared that this study received no financial support. 


\section{REFERENCES}

1. Chatoor D, Emmnauel A. Constipation and evacuation disorders. Best Pract Res Clin Gastroenterol 2009;23(4):517-30.

2. Kasap E, Bor S. Fonksiyonel barsak hastalığı prevalansı. Güncel Gastroenteroloji 2006;10(2):165-8.

3. Mugie SM, Benninga MA, Di Lorenzo C. Epidemiology of constipation in children and adults: A systematic review. Best Pract Res Clin Gastroenterol 2011;25(1):3-18.

4. Chu H, Zhong L, Li H et al. Epidemiology characteristics of constipation for general population, pediatric population, and elderly population in China. Gastroenterol Res Pract 2014;2014:532734.

5. Bharucha AE, Pemberton JH, Locke GR 3rd. American Gastroenterological Association technical review on constipation. Gastroenterology 2013;144(1):218-38.

6. Werth BL, Williams KA, Fisher MJ et al. Defining constipation to estimate its prevalence in the community: Results from a national survey. BMC Gastroenterol 2019;19(1):75.

7. Talley NJ, Weaver AL, Zinsmeister AR et al. Functional constipation and outlet delay: A population-based study. Gastroenterology 1993;105(3):781-90.

8. Schmulson MJ, Drossman DA. What is new in Rome IV. J Neurogastroenterol Motil 2017;23(2):151-63.

9. Simren M, Palsson OS, Whitehead WE. Update on Rome IV criteria for colorectal disorders: Implications for clinical practice. Curr Gastroenterol Rep 2017;19(4):15.

10. Russo M, Strisciuglio C, Scarpato E et al. Functional chronic constipation: Rome III criteria versus Rome IV criteria. J Neurogastroenterol Motil 2019;25(1):123-8.

11. Lewis SJ, Heaton KW. Stool form scale as a useful guide to intestinal transit time. Scand J Gastroenterol 1977;32(9):920-4.

12. Markland AD, Palsson O, Goode PS et al. Association of low dietary intake of fiber and liquids with constipation: Evidence from the National Health and Nutrition Examination Survey. Am J Gastroenterol 2013;108(5):796-803.
13. Dukas L, Wilett WC, Giovannucci EL et al. Association between physical activity, fiber intake, and other lifestyle variables and constipation in a study of women. Am J Gastroeneterol 2003;98(8):1790-6.

14. Jangid V, Godhia M, Sanwalka N et al. Water intake, dietary fibre, defecatory habits and its association with chronic functional constipation. Curr Res Nutr Food Sci 2016;4(2):90-5.

15. Arnaud MJ. Mild dehydration: A risk factor of constipation? Eur J Clin Nutr 2003;57(2):88-95

16. Dehn TC, Kettlewell MG. Haemorrhoids and defaecatory habits. Lancet 1989;1(8628):54-5

17. Goldstein $\mathrm{O}$, Shaham $\mathrm{Y}, \mathrm{Naftali} \mathrm{T}$ et al. Toilet reading habits in Israeli adults. Neurogastroenterol Motil 2009;21(3):291-5.

18. Berney CR. Smartphone lavatory syndrome. ANZ J Surg 2020;90(6):953-4

19. Çelik S. The Relationship between hemorrhoids and smartphone use lavatory. Study record. Department of General Surgery, Yüzüncü Yıl University Faculty of Medicine: 2018 Feb. Report No: NCT03444389. Available from: URL: https:// clinicaltrials.gov/ct2/show/NCT03444389.

20. Duboc H, Coffin B, Siproudhis L. Disruption of circadian rhythms and gut motility: An overview of underlying mechanisms and associated pathologies. J Clin Gastroenterol 2020;54(5):405-14

21. Bavarsad MB, Azimi N, Moradbeigi $\mathrm{K}$ et al. Associations between morningness-eveningness and sleep quality among female dormitory residents. Thrita 2015;4(1):25088.

22. Andone, I, Błaszkiewicz K, Eibes $\mathrm{M}$ et al. How age and gender affect smartphone usage. Proceedings of the 2016 ACM International Joint Conference on Pervasive and Ubiquitous Computing Adjunct - UbiComp '16; 2016, New York, NY, USA; 2016.p.9-12. 